\title{
Differences Between ADEA Annual Session Poster Abstracts and Their Corresponding Full Published Articles
}

\author{
Judy Chia-Chun Yuan, D.D.S., M.S.; Maria Therese S. Galang, D.M.D., M.S.; \\ Damian J. Lee, D.D.S., M.S.; Valentim A.R. Barao, D.D.S., M.Sc., Ph.D.; \\ Nodesh Shyamsunder, B.D.S.; Cortino Sukotjo, D.D.S., Ph.D., M.M.Sc.
}

Abstract: The purpose of this study was to investigate differences between abstracts of posters presented at the $79^{\text {th }}(2002)$ and $80^{\text {th }}$ (2003) Annual Session \& Exhibition of the American Dental Education Association (ADEA) and the published full-length articles resulting from the same studies. The abstracts for poster presentation sessions were downloaded, and basic characteristics of the abstracts and their authors were determined. A PubMed search was then performed to identify the publication of full-length articles based on those abstracts in a peer-reviewed journal. The differences between the abstract and the article were examined and categorized as major and minor differences. Differences identified included authorship, title, materials and methods, results, conclusions, and funding. Data were analyzed with both descriptive and analytic statistics. Overall, 89 percent of the abstracts had at least one variation from its corresponding article, and 65 percent and 76 percent of the abstracts had at least one major and minor variation, respectively, from its corresponding article. The most prevalent major variation was in study results, and the most prevalent minor variation was change in the number of authors. The discussion speculates on some possible reasons for these differences.

Dr. Yuan is Assistant Professor, Department of Restorative Dentistry, College of Dentistry, University of Illinois at Chicago; Dr. Galang is Assistant Professor of Orthodontics, College of Dentistry, University of Illinois at Chicago; Dr. Lee is Assistant Professor, Department of Restorative Dentistry, College of Dentistry, University of Illinois at Chicago; Dr. Barao is a researcher, Department of Dental Materials and Prosthodontics, Aracatuba Dental School, Univ. Estadual Paulista; Dr. Shyamsunder is a resident, Advanced Education in Prosthodontics Program, College of Dental Medicine, Nova Southeastern University; and Dr. Sukotjo is Assistant Professor, Department of Restorative Dentistry, College of Dentistry, University of Illinois at Chicago. Direct correspondence and requests for reprints to Dr. Cortino Sukotjo, Department of Restorative Dentistry, College of Dentistry (MC 555), University of Illinois at Chicago, 801 South Paulina Street, Room 365B, Chicago, IL 60612-7211; 312-355-0360 phone; 312-996-3535 fax; csukotjo@uic.edu.

Keywords: publication, published article, abstract, poster presentation, dental education

Submitted for publication 8/2/10; accepted 3/14/11

$\mathrm{T}$ The American Dental Education Association (ADEA) holds an Annual Session \& Exhibition every year for dental, allied dental, and advanced dental educators and students to gather to improve themselves and advance their profession. During the meeting, poster presentation sessions provide an opportunity for attendees to exchange new ideas and educational research. The poster abstracts are peer-reviewed, and all are published in the Journal of Dental Education except those categorized as Works in Progress. (All information about the abstracts was taken from the ADEA website on May 8, 2010.) Abstracts usually provide limited and/or preliminary information, ${ }^{1,2}$ and the restricted size may be inadequate to convey all aspects of the study, describe the data interpretation, or explain its application to clinical practice. ${ }^{3}$ Final conclusions from a study are therefore more appropriately drawn from full-length articles. The benefits of article publication include the more extensive opportunity for the author to describe the details and implications of the study; the wider dissemination of knowledge among dental and other educators; ${ }^{4}$ and the support published work provides for faculty members seeking promotion and tenure. ${ }^{5}$

Not all poster abstracts are published as fulllength articles after scientific or educational meetings. Some groups that have investigated the publication rate of articles based on abstracts presented at health professions meetings found it ranged from 10 percent to 78 percent. $^{3,6-15}$ Others have examined the barriers to developing abstracts into full-length 
articles, ${ }^{4,14,16,17}$ identifying such reasons as lack of preparation time, ongoing study, and challenging relationships between coauthors. Still others have noted differences between the abstracts and their corresponding full-length articles. ${ }^{3,9,13,14,18,19}$ The many differences between the two should prompt readers to be cautious about interpretation of data from abstracts ${ }^{20}$ and referencing abstracts in scientific communications. ${ }^{3,9,13,16}$ Differences between abstracts and full-length articles in the dental literature have apparently received little attention. ${ }^{3}$

Our previous study examined demographic and other data of abstracts presented at two consecutive ADEA Annual Sessions. ${ }^{15}$ Factors that seemed to influence the expansion of abstracts into full-length articles and their publication rate were evaluated. To provide more insight into this aspect of dental education, we conducted a study to investigate the differences between the poster abstracts presented at the $79^{\text {th }}(2002)$ and $80^{\text {th }}(2003)$ ADEA Annual Session \& Exhibition and their corresponding published articles regarding authorship, title, materials and methods, results, conclusions, and funding.

\section{Materials and Methods}

Abstracts from these poster presentations were downloaded from the Journal of Dental Education $(J D E)$ website. The abstracts were divided among the six investigators, and each extracted data independently. To ensure reliability among the six, calibration meetings were held on a regular basis to ensure that all determinations coincided. If a decision could not be made, group discussion led to consensus. All abstracts not related to education (i.e., basic science research) were excluded from the study. For each included abstract, the investigator collected basic characteristics: title, authorship (number of authors, name of first author), purpose, materials and methods, sample size, statistical analysis, study results, study outcome, study conclusions, and sources of funding.

To identify the publication of a full article based on the abstract in a peer-reviewed journal, a search of PubMed was performed. When multiple publications were identified, Boolean operator (AND) was used to combine author names and keywords from the abstract title to obtain the correct article. ${ }^{3}$ Since previous studies have reported a five-year interval to be an average time frame for publication of full articles based on abstracts presented at scientific meetings, ${ }^{6,10,12}$ we restricted our search to five years after each meeting.

Differences between the abstract and the published article were identified in the categories of title, authorship (number of authors, name of first author), purpose, materials and methods, sample size, statistical analysis, study results, study outcome, study conclusions, and sources of funding. The classification of each independent variable was adapted from previous publications with some modifications. ${ }^{9,13,21,22}$ Any change in the title was documented, except for minor changes such as addition or deletion of a pronoun and use of punctuation. ${ }^{21}$ Differences in the sample size were recorded, and the extent of difference was noted. If the sample size was not mentioned in the abstract, it was assigned "not applicable" for the category. If a difference between the study results was observed, statistically significant changes were identified. Differences between the abstract and the full-length article were then categorized as major or minor variations and were subsequently quantified. ${ }^{13}$ Major differences consisted of changes in the study purpose, materials and methods, sample size, statistical analysis, study results, study outcome, and conclusions. Minor differences included changes in the title, number of authors, name of first author, and sources of funding.

Data were entered into a software database (Microsoft Excel 2003, Microsoft, Seattle, WA). The software Statistical Package for the Social Sciences, version 17.0 (SPSS Inc., Chicago, IL) was used for the statistical analysis. Data were analyzed with both descriptive and analytic statistics. Frequencies and percentages were calculated for the identified characteristics in the abstracts and articles. Major and minor differences between the abstract and its corresponding article were calculated. Mann-Whitney U tests were conducted to examine the relationships between variables. Statistical significance was set at $\mathrm{p}<0.05$.

\section{Results}

A total of 370 abstracts met the inclusion criteria for this study. One abstract ( 0.3 percent) was not related to education and was excluded. A total of seventy-one articles were identified.

Sixty-three (89 percent) of seventy-one published articles had at least one variation from their corresponding abstracts. Forty-six (65 percent) and fifty-four (76 percent) of the published articles had at least one major and one minor variation, respectively 
(Table 1). Twenty (28 percent) published articles had at least three major variations, and thirty-one (44 percent) had at least two minor variations. The median number of major and minor differences between the abstract and the published article was one (range 0-6) and one (range 0-3), respectively.

The number and percentage of the major and minor differences are listed in Table 2. Nine abstracts (13 percent) did not mention sample size and were assigned to a "not-applicable" category. The most prevalent major difference was the study results $(n=25,35$ percent), followed by conclusions $(n=21$, 30 percent). The most common minor difference was change in the number of authors $(n=33,46$ percent), followed by change of title ( $n=25,35$ percent). The average number of authors increased from the abstracts $(2.9 \pm 1.2)$ to their corresponding articles (3.1 \pm 1.3$)$. There was no statistically significant difference between the number of authors of the abstracts $(\mathrm{Md}=3, \mathrm{n}=71)$ and the published articles $(\mathrm{Md}=3$, $n=71), U=2200, z=-1.36, p=0.175$. Overall, the most consistent categories between the abstract and the published article were materials and methods $(n=61$, 86 percent) and study outcome ( $\mathrm{n}=61,86$ percent), followed by funding ( $\mathrm{n}=60,85$ percent).

\section{Discussion}

The differences between abstracts presented at the 2002 and 2003 ADEA Annual Session \& Exhibition and their corresponding published articles were evaluated, and variations were noted. This study found that minor variations were more prevalent than major variations. This finding is similar to that found in previous studies. ${ }^{13,14,17}$ Kleweno et al. ${ }^{13}$ found that 63 percent of the abstracts from the American Academy of Orthopaedic Surgeons Annual Meeting had at least one major difference and 81 percent had at least one minor difference from their corresponding published articles. Cartwright et al. ${ }^{17}$ reported a similar trend but a much lower prevalence of 18 percent major differences and 55 percent minor differences between abstracts from the International Continence Society Meeting and the corresponding published articles. Balasubramanian et al. ${ }^{14}$ found that 6 percent of the abstracts from the Association of Surgeons of Great Britain and Ireland Annual Meeting had at least one major difference and 86 percent had at least one minor difference from their corresponding published articles.

The most prevalent major difference observed in our study was the difference in study results. The proportion of difference ( 35 percent) we found on this parameter was higher than the range of 3 to 33 percent difference reported in the results of other studies. ${ }^{9,13,14}$ One explanation could be the high proportion of differences in the sample size, which may consequently modify the study results and conclusions. ${ }^{13}$ A possible explanation for this difference may be that the posters were actually based on research that was in progress even though not identified as a "Work in Progress" in the poster labeling and thus the increased sample size was a normal progression. Alternatively, these authors may have decided to expand their studies for a variety of reasons, including the discussions with attendees that are one of the goals of the poster presentations. Only a few studies in our sample decreased in sample size from the abstract to the published article. Since our study did not further examine the reasons for difference in sample size, no conclusion can be drawn regarding this factor. It is curious that the differences between abstracts and their corresponding articles regarding study results did not track with differences in study outcomes or conclusions. It could be that this inconsistency reveals an interpretation bias in the study.

Table 1. Major and minor differences between full-length articles and their corresponding abstracts presented at the ADEA Annual Session \& Exhibition, by number of articles and percentage of total articles $(\mathrm{N}=71)$

\begin{tabular}{|c|c|c|c|c|c|}
\hline $\begin{array}{c}\text { Variable } \\
\text { Differences }\end{array}$ & $\begin{array}{l}\text { Major } \\
\text { N (\%) }\end{array}$ & $\begin{array}{l}\text { Minor } \\
\text { N (\%) }\end{array}$ & $\begin{array}{l}\text { Cumulative } \\
\text { Differences }\end{array}$ & $\begin{array}{l}\text { Major } \\
\text { N (\%) }\end{array}$ & $\begin{array}{l}\text { Minor } \\
\text { N (\%) }\end{array}$ \\
\hline 0 & $25(35 \%)$ & $17(24 \%)$ & & $25(35 \%)$ & $17(24 \%)$ \\
\hline 1 & $15(21 \%)$ & $23(32 \%)$ & $\geq 1$ & $46(65 \%)$ & $54(76 \%)$ \\
\hline 2 & $11(16 \%)$ & $25(35 \%)$ & $\geq 2$ & $31(44 \%)$ & $31(44 \%)$ \\
\hline 3 & $6(8 \%)$ & $6(9 \%)$ & $\geq 3$ & $20(28 \%)$ & $6(9 \%)$ \\
\hline 4 & $4(6 \%)$ & & $\geq 4$ & $14(20 \%)$ & \\
\hline 5 & $4(6 \%)$ & & $\geq 5$ & $10(14 \%)$ & \\
\hline 6 & $6(8 \%)$ & & & & \\
\hline
\end{tabular}


Among the minor differences identified, our study found nearly 50 percent differences in authorship - namely, in increased number of authors. Poster submissions to the ADEA Annual Session $\&$ Exhibition limit the number of first authorships to two submissions: that is, a poster author may be the first author of at most two poster abstracts. For that and other reasons, the final order of authors by contribution to the study as described in a full article may be different from the order submitted with the poster abstract. Previous studies have reported changes in authorships ranging from 30 percent to 40 percent. ${ }^{3,9,13,20}$ The substantial differences in authorship between the abstracts and the later articles in many disciplines may be attributable to the fact that abstracts are written for the poster presentation, which is often work in progress. Also, when authors submit their full articles as manuscripts for publication, their work is reviewed, and the authors make changes based on the feedback, which may lead to changes in the list of authors and their relative contributions to the final publication.

The findings of this study should be interpreted with caution for at least a couple of reasons. First, the ADEA poster submission process sets a word limit on the abstracts but does not require a specific format or inclusion parameters such as statistical analysis of data or a certain sample size. Although the submitted abstracts are peer-reviewed, feedback from the reviewers is not made available to the authors; therefore, modifications of abstracts are not possible. Also, the scholarly requirements for poster abstracts are much more general and flexible than those for article acceptance. Although the evaluation standards for acceptance may differ, they do not necessarily conflict; however, the acceptance rate for posters most likely reflects a desire to encourage a larger number in order to foster exchanges of new ideas and research findings even if preliminary. Other studies have found the differences between abstracts and published articles to be a result of the authors' efforts to improve their research findings before publication ${ }^{13}$ or the fact that abstracts are often based on preliminary data. ${ }^{14,21}$ Since posters generally serve a different purpose from that of full articles, they are reviewed in a different manner. The differences between the abstracts and their corresponding articles should therefore not necessarily suggest that the abstracts are poorer in quality than the articles but, instead, are more limited in interpretation.

Second, educational research is different from basic science and clinical research in study design, methodology, and the topics studied. ${ }^{23-27}$ Dental education research projects are designed mainly as observational and curriculum-focused, which may use different methodologies and study designs than in basic science or clinical research. ${ }^{27}$ This difference in study design may help explain structural

Table 2. Differences between abstracts and published articles, by number and percentage for each type of difference

\begin{tabular}{|c|c|c|}
\hline & N (Total=71) & Percentage \\
\hline \multicolumn{3}{|l|}{ MAJOR VARIABLES } \\
\hline \multicolumn{3}{|l|}{ Purpose } \\
\hline Same & 57 & $80 \%$ \\
\hline Different & 14 & $20 \%$ \\
\hline \multicolumn{3}{|l|}{ Materials and Methods } \\
\hline Same & 61 & $86 \%$ \\
\hline Different & 10 & $14 \%$ \\
\hline \multicolumn{3}{|l|}{ Sample Size } \\
\hline Same & 44 & $62 \%$ \\
\hline Different & 18 & $25 \%$ \\
\hline - Increase & 15 & $21 \%$ \\
\hline - Decrease & 3 & $4 \%$ \\
\hline Not applicable & 9 & $13 \%$ \\
\hline \multicolumn{3}{|l|}{ Statistical Analysis } \\
\hline Same & 51 & $72 \%$ \\
\hline Different & 14 & $20 \%$ \\
\hline Not applicable & 6 & $8 \%$ \\
\hline \multicolumn{3}{|l|}{ Study Results } \\
\hline Same & 46 & $65 \%$ \\
\hline $\begin{array}{l}\text { Different, but no change of } \\
\text { statistical significance }\end{array}$ & ff & $7 \%$ \\
\hline $\begin{array}{l}\text { Different, with change of } \\
\text { statistical significance }\end{array}$ & 20 & $28 \%$ \\
\hline \multicolumn{3}{|l|}{ Study Outcome } \\
\hline Same & 61 & $86 \%$ \\
\hline Different & 10 & $14 \%$ \\
\hline \multicolumn{3}{|l|}{ Conclusions } \\
\hline Same & 50 & $70 \%$ \\
\hline Different & 21 & $30 \%$ \\
\hline \multicolumn{3}{|l|}{ MINOR VARIABLES } \\
\hline \multicolumn{3}{|l|}{ Title } \\
\hline Same & 46 & $65 \%$ \\
\hline Different & 25 & $35 \%$ \\
\hline \multicolumn{3}{|l|}{ Number of Authors } \\
\hline Same & 38 & $54 \%$ \\
\hline Different & 33 & $46 \%$ \\
\hline - Increase & 22 & $31 \%$ \\
\hline - Decrease & 11 & $15 \%$ \\
\hline \multicolumn{3}{|l|}{ First Author } \\
\hline Same & 48 & $68 \%$ \\
\hline Different & 23 & $32 \%$ \\
\hline \multicolumn{3}{|l|}{ Funding } \\
\hline Same & 60 & $85 \%$ \\
\hline Different & 11 & $15 \%$ \\
\hline
\end{tabular}


differences in presenting data and scientific writing from that in basic science or clinical research. In the two journals (the JDE and the European Journal of Dental Education) reviewed in a related study, dental education studies were found to be primarily descriptive in nature, and experimental study designs were not commonly observed. ${ }^{27}$ With these differences in methodology and topics of interest, comparisons between clinical and educational research should be made cautiously. Readers should also be cautious about interpreting data from poster abstracts as these may not include comprehensive information or final results. ${ }^{20}$ For all these reasons, other studies have argued that references to abstracts in scientific communications should be minimized, ${ }^{3,9,13,16}$ a caution that should be considered for dental education as well.

Studies in medicine have occasionally recommended that more structured abstract requirements should be used to improve abstract submissions. ${ }^{1,2,8,21}$ It has also been argued that structured abstracts in medicine provide higher quality information, ${ }^{28}$ facilitate the peer review process, ${ }^{1}$ and make it easier for readers to identify articles relevant for their use. ${ }^{29}$ An eight-heading format of structured abstracts (objective, design, setting, patients, intervention, main outcome measures, results, and conclusions) has been proposed for original articles. ${ }^{30}$ Although educational research often has a different research methodology from that used in clinical medicine, it may be that such a format could be modified for the reporting of educational studies and might be useful for the ADEA poster abstract submission process.

Some limitations should be kept in mind when interpreting these findings. This study did not examine the rationale nor analyze the reasons for the differences between abstracts and their corresponding articles. Understanding the reasons for these differences would help readers evaluate the findings. Furthermore, the search for published articles was limited to PubMed only, so those journals not indexed in PubMed were not included for data analysis. Finally, this study did not evaluate the relationship of time to publication and differences as reported in previous studies. ${ }^{9}{ }^{14}$ Such an examination might provide more insight into the differences between the ADEA abstracts and their corresponding articles.

\section{Acknowledgments}

The authors wish to thank Drs. Anne Koerber and John Crawford for their invaluable input on the manuscript for this article.

\section{REFERENCES}

1. Froom P, Froom J. Deficiencies in structured medical abstracts. J Clin Epidemiol 1993;46(7):591-4.

2. Taddio A, Pain T, Fassos FF, Boon H, Ilersich AL, Einarson TR. Quality of nonstructured and structured abstracts of original research articles in the British Medical Journal, the Canadian Medical Association Journal, and the Journal of the American Medical Association. CMAJ 1994;150(10):1611-5.

3. Dahllof G, Wondimu B, Maniere MC. Subsequent publication of abstracts presented at the International Association of Paediatric Dentistry meetings. Int J Paediatr Dent 2008;18(2):91-7.

4. Sprague S, Bhandari M, Devereaux PJ, Swiontkowski MF, Tornetta P 3rd, Cook DJ, et al. Barriers to full-text publication following presentation of abstracts at annual orthopaedic meetings. J Bone Joint Surg Am 2003;85A(1): 158-63.

5. Masella RS, Thompson TJ. Dental education and evidencebased educational best practices: bridging the great divide. J Dent Educ 2004;68(12):1266-71.

6. Bagheri SC, Lenox N, Verschueren DS, Holmgren E, Kademani D, Bell RB, Dierks EJ. Abstracts from the American Association of Oral and Maxillofacial Surgeons annual scientific meeting: proportion published and time to publication. J Oral Maxillofac Surg 2005;63(6):838-40.

7. Scherer RW, Langenberg P, von Elm E. Full publication of results initially presented in abstracts. Cochrane Database Syst Rev 2007(2):MR000005.

8. Scholey JM, Harrison JE. Delay and failure to publish dental research. Evid Based Dent 2005;6(3):58-61.

9. Bhandari M, Devereaux PJ, Guyatt GH, Cook DJ, Swiontkowski MF, Sprague S, Schemitsch EH. An observational study of orthopaedic abstracts and subsequent full-text publications. J Bone Joint Surg Am 2002;84-A(4):615-21.

10. Hamlet WP, Fletcher A, Meals RA. Publication patterns of papers presented at the annual meeting of the American Academy of Orthopaedic Surgeons. J Bone Joint Surg Am 1997;79(8):1138-43.

11. Jackson KR, Daluiski A, Kay RM. Publication of abstracts submitted to the annual meeting of the Pediatric Orthopaedic Society of North America. J Pediatr Orthop 2000;20(1):2-6.

12. Wang JC, Yoo S, Delamarter RB. The publication rates of presentations at major spine specialty society meetings (NASS, SRS, ISSLS). Spine 1999;24(5):425-7.

13. Kleweno CP, Bryant WK, Jacir AM, Levine WN, Ahmad CS. Discrepancies and rates of publication in orthopaedic sports medicine abstracts. Am J Sports Med 2008;36(10):1875-9.

14. Balasubramanian SP, Kumar ID, Wyld L, Reed MW. Publication of surgical abstracts in full text: a retrospective cohort study. Ann R Coll Surg Engl 2006;88(1):57-61.

15. Galang MTS, Yuan JC, Lee DJ, Barao VAR, Shyamsunder N, Sukotjo C. Factors influencing publication rates of abstracts presented at the ADEA Annual Session \& Exhibition. J Dent Educ 2011;75(4):549-56.

16. International Committee of Medical Journal Editors. Uniform requirements for manuscripts submitted to 
biomedical journals: writing and editing for biomedical publication (October 2008). At: www.icmje.org. Accessed: February 13, 2011.

17. Cartwright R, Khoo AK, Cardozo L. Publish or be damned? The fate of abstracts presented at the International Continence Society Meeting 2003. Neurourol Urodyn 2007;26(2):154-7.

18. Knobloch K. Discrepancies and rates of publication in orthopaedic sports medicine abstracts. Am J Sports Med 2009;37(3):e1-2.

19. Preston CF, Bhandari M, Fulkerson E, Ginat D, Egol KA, Koval KJ. The consistency between scientific papers presented at the Orthopaedic Trauma Association and their subsequent full-text publication. J Orthop Trauma 2006;20(2):129-33.

20. Weintraub WH. Are published manuscripts representative of the surgical meeting abstracts? An objective appraisal. J Pediatr Surg 1987;22(1):11-3.

21. Zelle BA, Zlowodzki M, Bhandari M. Discrepancies between proceedings abstracts and posters at a scientific meeting. Clin Orthop 2005;435:245-9.

22. Hasenboehler EA, Choudhry IK, Newman JT, Smith WR, Ziran BH, Stahel PF. Bias towards publishing positive results in orthopedic and general surgery: a patient safety issue? Patient Saf Surg 2007;1(1):4.
23. Derossis AM, DaRosa DA, Dutta S, Dunnington GL. A ten-year analysis of surgical education research. Am J Surg 2000;180(1):58-61.

24. Dimitroff A, Davis WK. Content analysis of research in undergraduate medical education. Acad Med 1996;71(1):60-7.

25. Eva KW. Issues to consider when planning and conducting educational research. J Dent Educ 2004;68(3):316-23.

26. Regehr G. Trends in medical education research. Acad Med 2004;79(10):939-47.

27. Sukotjo C, Yuan JC, Bordage G. A content analysis of dental education research as reported in two journals. $\mathrm{J}$ Dent Educ 2010;74(10):1106-12.

28. Sharma S, Harrison JE. Structured abstracts: do they improve the quality of information in abstracts? Am J Orthod Dentofacial Orthop 2006;130(4):523-30.

29. Ad Hoc Working Group for Critical Appraisal of the Medical Literature. A proposal for more informative abstracts of clinical articles. Ann Intern Med 1987;106(4):598-604.

30. Haynes RB, Mulrow CD, Huth EJ, Altman DG, Gardner MJ. More informative abstracts revisited. Ann Intern Med 1990;113(1):69-76. 